Public Abstract

First Name:Elmar

Middle Name:

Last Name:Dohnke

Adviser's First Name:Peter

Adviser's Last Name:Pfeifer

Co-Adviser's First Name:

Co-Adviser's Last Name:

Graduation Term:SP 2015

Department:Physics

Degree:PhD

\title{
Title:ON THE HIGH DENSITY HYDROGEN FILMS ADSORBED IN CARBON NANOSPACES
}

The commercialization of hydrogen-powered fuel cell cars, with their environmentally friendly emissions, provides an opportunity to replace current gasoline powered vehicles. The main drawback of hydrogen as a fuel is the low density at ambient temperatures. The gas needs to be compressed to high pressure or kept under cryogenic temperatures to achieve reasonably long driving ranges. These obstacles can be overcome if the tanks are filled with a porous material that adsorbs a high volume of hydrogen. To get a better understanding of the materials performance, an attempt was made to analyze the properties of the adsorbed hydrogen film. High pressure hydrogen isotherms at cryogenic temperatures ( $77 \mathrm{~K}, 50 \mathrm{~K})$ have been studied to estimate adsorbed film properties such as density and thickness. In most of the samples saturated hydrogen film densities exceed the liquid hydrogen density at 1 bar and 20 Kelvin by $40 \%$. Additionally a new method was developed to estimate specific surface areas of gas storage materials from high pressure isotherms and tested against the BET theory. The new method does not require knowledge of the packing fraction or cross-sectional area of an adsorbed molecule in the film. In most cases the new method leads to surface areas comparable to those found using BET theory if cryogenic high pressure isotherms are used. 